\title{
INFERIOR CERVICAL GANGLION AND STELLATE GANGLION- CONCEPTS REVISITED
}

\author{
Vandana Latha Raveendran¹, Girija Kumari Kamalamma²
}

${ }_{1}^{1}$ Assistant Professor, Department of Anatomy, Government Medical College, Thiruvananthapuram, Kerala.

2Professor and HOD, Department of Anatomy, Sree Mookambika Institute of Medical Sciences, Kanyakumari, Tamilnadu.

\section{BACKGROUND}

ABSTRACT

Awareness of the regional anatomy of the cervical sympathetic chain may help the surgeons in identifying and preserving this structure during related surgical procedures. Care must be taken by the spinal surgeon to protect the chain and its branches, while dissecting the longus colli muscle especially in the root of neck for anterior spinal surgeries. ${ }^{1}$

The present study aims to define the lower two ganglia, i.e. inferior cervical ganglion and stellate ganglion by tracing their vascular relations, dimensions and branches. The frequency of occurrence of these ganglia, which is surgically significant is also studied.

\section{MATERIALS AND METHODS}

The study was descriptive, done in 50 cervical sympathetic chains by bilateral neck dissection of 25 adult cadavers in the Department of Anatomy, Medical College, Thiruvananthapuram. The superior cervical ganglion (SCG), inferior cervical ganglion (ICG), stellate ganglion (SG) and the intermediate ganglia were carefully dissected out and studied.

\section{RESULTS}

SCG was seen in $100 \%$ cases, middle inferior ganglion (MCG) in 44\%, vertebral ganglion (VG) in 72\%, ICG in $72 \%$ cases and stellate ganglion in $28 \%$ chains. The branches arising from the ganglia were Gray rami communicantes (GRC), vascular branches and medial visceral branches. Vertebral nerve from ICG was present in $4 \%$ cases and from stellate in $2 \%$ cases.

\section{CONCLUSION}

In the lower part of cervical sympathetic chain, ICG is more frequently present than SG.

\section{KEYWORDS}

Cervical Sympathetic Chain, Cervical Sympathetic Ganglia, Inferior Cervical Ganglion, Stellate Ganglion, Vertebral Nerve.

HOW TO CITE THIS ARTICLE: Raveendran VL, Kamalamma GK. Inferior cervical ganglion and stellate ganglion- concepts revisited. J. Evolution Med. Dent. Sci. 2018;7(13):1653-1658, DOI: 10.14260/jemds/2018/373

\section{BACKGROUND}

The cervical sympathetic chain lies ventral to the transverse process of the cervical vertebrae and dorsal to the carotid vessels. It extends from the base of the skull to the level of the neck of first rib, where it continues as the thoracic sympathetic chain. The classical chain was described as having 3 ganglion masses named as superior cervical ganglion, middle cervical ganglion and inferior cervical ganglion or cervico-thoracic ganglion. The varying frequency of occurrence of ICG and SG is mentioned in the previous studies, leaving a questionable concept that will the ICG and first thoracic ganglion almost universally fused to form the stellate ganglion.

The ganglia in the cervical region were named as "ganglion cervical medium" and "ganglion cervicothoracicum" or "ganglion stellatum" in the International Anatomical Nomenclature Committee [Nomina Anatomica, Paris (1955)]. The term "inferior cervical ganglion" had been discarded in Nomina Anatomica and was justified by the fact that the "inferior cervical ganglion" appeared only exceptionally as an independent formation. ${ }^{2}$

'Financial or Other Competing Interest': None.

Submission 17-02-2018, Peer Review 12-03-2018,

Acceptance 19-03-2018, Published 26-03-2018.

Corresponding Author:

Vandana Latha Raveendran,

Assistant Professor, Department of Anatomy,

Government Medical College, Thiruvananthapuram, Kerala

E-mail: drvandanalr@gmail.com

DOI: $10.14260 /$ jemds $/ 2018 / 373$
In blind procedures like stellate ganglion blocks, the accidental injection of the anaesthetic agents to these ganglia might lead to sudden hypotension and even death if immediate medical intervention was not provided. The lack of a detailed knowledge of its occurrence, branching pattern and vascular relations will lead to iatrogenic injury complicating many surgical procedures in the root of neck. ${ }^{3}$

\section{MATERIALS AND METHODS}

The study was descriptive. The materials used for the present study were the 25 formalin fixed adult cadavers from the Department of Anatomy, Medical College, Thiruvananthapuram. 50 cervical sympathetic chains were studied over a period of 2 years with appropriate ethical approval from the Ethical Committee of the Medical College, Thiruvananthapuram. Carotid sheath was dissected in the anterior triangle following the conventional dissection steps. Cervical sympathetic chain was exposed deep to the sheath from the base of skull to the level of neck of second rib. All the ganglia seen and their branches were dissected taking care to preserve all its finer connections with the help of a head loupe of $2 x$ magnification. Length, breadth and thickness of ganglia were measured with vernier caliper. Various parameters like shape, location, branches, vascular relations and communications of all cervical ganglia were noted. All the measurements were tabulated. The descriptive statistics like mean and standard deviation were calculated. 


\section{RESULTS}

A ganglionated cord was observed in all the specimens studied, lying over the longus colli muscle extending from the base of skull to the level of neck of first rib. The presence of SCG was a constant finding in all cases. In $72 \%$ cases, it lies over the transverse process of second and third cervical vertebrae giving GRC to first 4 cervical spinal nerves.

The MCG was present in 22 (44\%) cases, closely related to ITA, most frequently at the level of sixth cervical vertebral body $(50 \%)$ giving GRC to $6^{\text {th }}$ cervical spinal nerve in $31.8 \%$ cases and to $5^{\text {th }}$ and $6^{\text {th }}$ cervical spinal nerves in $27.3 \%$ cases. In cases where no GRC arises from ganglion, it was seen arising from chain itself. Tracheo-oesophageal branches and cardiac branches were given as medial branches. Vascular branches were seen forming plexus over inferior thyroid artery in all the 22 cases.

The vertebral ganglion was observed in $36(72 \%)$ cases frequently at $7^{\text {th }}$ cervical vertebral body level, closely related anterior to vertebral artery forming plexus over it. Lateral branches as GRC to the seventh cervical spinal nerve were seen in $38.9 \%$ cases. Tracheo-oesophageal branches, cardiac branches and vascular branches forming plexus over the vertebral artery were present in all the 36 cases.

In $36(72 \%)$ cases, an irregular ganglion was seen at the posteromedial aspect of the root of vertebral artery (Fig. 1). The length, breadth and the average thickness were $0.82+/$ $0.3 \mathrm{~cm}, 0.5+/-0.2 \mathrm{~cm}$ and $0.25 \mathrm{~cm}$ respectively. This inferior most cervical ganglion was seen at the level of the seventh cervical vertebral body in $24(66.7 \%)$ cases and extending over the neck of first rib in 12 cases. This ganglion gave lateral branches as GRC to $7^{\text {th }}$ and $8^{\text {th }}$ cervical spinal nerves in 17 cases and to $8^{\text {th }}$ cervical spinal nerve only in 19 cases. Vertebral nerve was seen in 2 cases arising from this ganglion and entering the foramen transversarium (Fig. 2). Medial branches were given as cardiac branches in 33 cases and they formed plexus with the cardiac nerves from the SCG, MCG and from the cord in 3 cases. Tracheo-oesophageal branches, 1 or 2 in number were seen arising in 16 cases. Vascular branches formed plexus over vertebral artery and to subclavian artery ( $1^{\text {st }}$ part $)$ in all the cases.

In $14(28 \%)$ cases, behind the 1 st part of subclavian artery a ganglion was seen as an irregular mass with constrictions (Fig. 3). The length of ganglion was $1.67+/-0.4 \mathrm{~cm}$, breadth was $0.66+/-0.2 \mathrm{~cm}$ and the average thickness was $0.3 \mathrm{~cm}$. The location of this ganglion in $85.7 \%$ cases was over the transverse process of 7 th cervical vertebrae extending to the neck of $1^{\text {st }}$ rib making it a cervicothoracic ganglion. Branches were as follows: Lateral branches in $9(64.3 \%)$ cases, the GRC to $7^{\text {th }}$ and $8^{\text {th }}$ cervical and $1^{\text {st }}$ thoracic spinal nerves were seen (Fig. 4). In addition to these, GRC to the $2^{\text {nd }}$ thoracic spinal nerve was also seen in $7.1 \%$ cases (Fig. 5). Vertebral nerve was seen arising from this ganglion in 1 case (Fig. 6). Medial branches: Cardiac branches were present in 3 cases only. Vascular branches: 2 or 3 branches originated from the ganglion and formed plexus over the $1^{\text {st }}$ part of subclavian artery in all the cases.

Cord below middle ganglia was seen double in all the cases studied. The anterior cord encircling the subclavian artery, ansa subclavia was observed in all the 50 cases. It was seen arising from the VG in $70 \%$ cases and from the MCG in $14 \%$ cases winding round the first part of the subclavian artery and getting connected to the ganglion below. Ansa was seen connecting ICG to ICG in $4 \%$ and SG to SG in $8 \%$ cases (Fig. 3). The posterior cord was seen extending posterior to the subclavian artery, as the continuation of the cervical sympathetic chain from the lower pole of ganglion above the upper pole of ganglion below (ICG or stellate ganglion). The average length of it was $0.78 \mathrm{~cm}$. No gray ramus or branches were seen originating from this.

\begin{tabular}{|c|c|c|}
\hline & ICG (36 Cases) & SG (14 Cases) \\
\hline GRC & $\begin{array}{c}\text { C7, C8 }(47.2 \%) \\
\text { C8 }(52.7 \%) \\
\text { Vertebral nerve }(5.6 \%)\end{array}$ & $\begin{array}{c}\text { C6, C7, C8, T1 } \\
(21.4 \%) \\
\text { C7, C8, T1 (64.3\%) } \\
\text { C7, C8, T1, T2 (7.1\%) } \\
\text { C8, T1 (7.1\%) } \\
\text { Vertebral N }(7.1 \%)\end{array}$ \\
\hline $\begin{array}{l}\text { Vascular } \\
\text { branches }\end{array}$ & $\begin{array}{l}\text { Over verteb } \\
\text { subclavian }\end{array}$ & $\begin{array}{l}\text { Over subclavian } \\
\text { artery }(100 \%)\end{array}$ \\
\hline $\begin{array}{l}\text { Medial } \\
\text { branches }\end{array}$ & $\begin{array}{l}\text { Tracheo-oesophageal }(16 \\
\text { cases), Cardiac (33 cases) }\end{array}$ & Cardiac ( 3 cases) \\
\hline \multicolumn{3}{|c|}{$\begin{array}{l}\text { Table 1. The branching Pattern of Two Ganglia } \\
\text { (ICG and SG) }\end{array}$} \\
\hline
\end{tabular}

\begin{tabular}{|c|c|c|}
\hline & ICG (\%) & SG (\%) \\
\hline Siwe (1931), Sheehan (1933) ${ }^{4}$ & 62.3 & 37.7 \\
\hline Perlow and Vehe (1935)5 & - & 80 \\
\hline Pick and Sheehan (1946) ${ }^{6}$ & & $75-80$ \\
\hline Jamieson et al (1952)7 & & 80 \\
\hline Becker and Grunt (1957) ${ }^{8}$ & 62.3 & 37.7 \\
\hline Hoffman (1957) & & 100 \\
\hline Jith and Mukherjee (1960) & & $75-80$ \\
\hline Ellison and Williams (1969) ${ }^{9}$ & & 88 \\
\hline Present Study & 72 & 28 \\
\hline
\end{tabular}

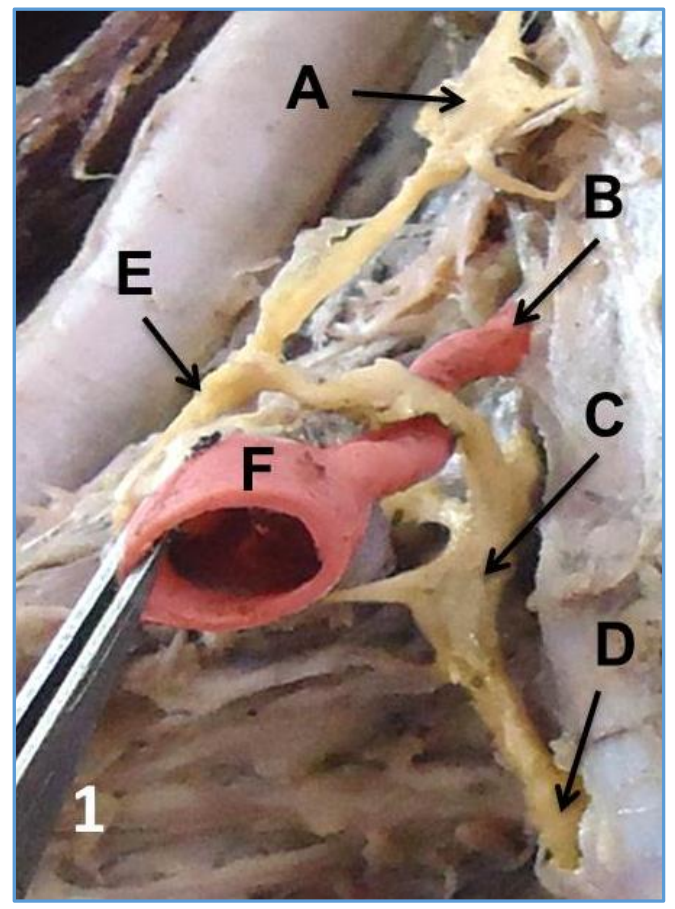

Figure 1. Right Cervical Sympathetic Chain with ICG
A. MCG
B. Vertebral Artery with Vertebral Ganglion
C. ICG
D. T1 Ganglion
E. Ansa Subclavia
F. Subclavian Artery 


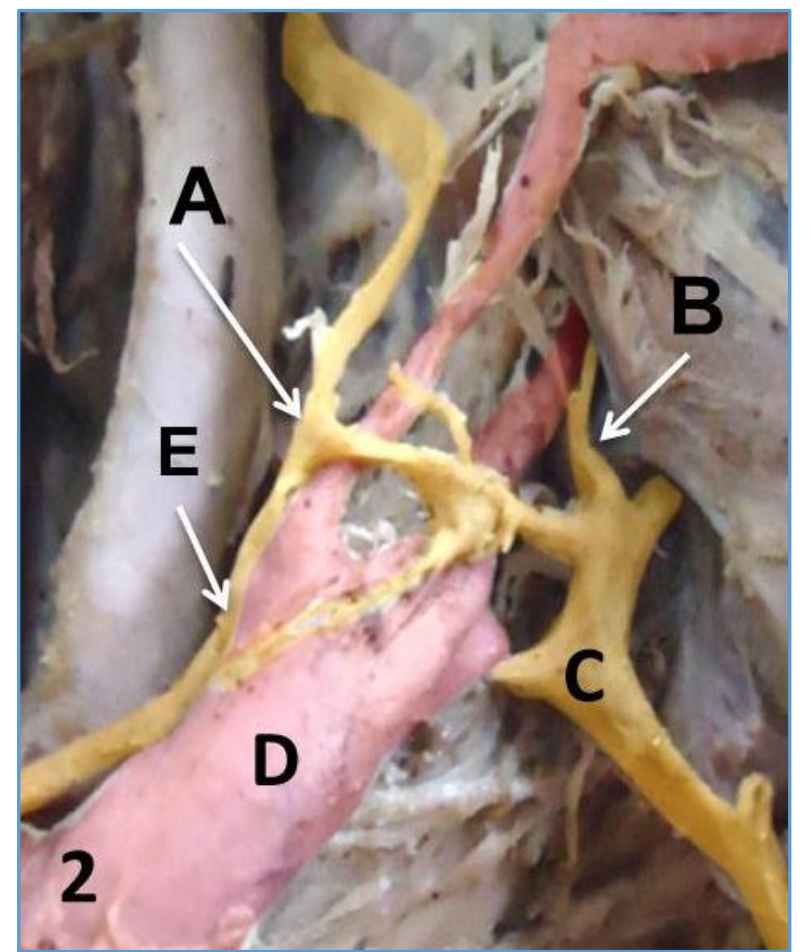

Figure 2. Right Cervical Sympathetic Trunk with ICG

A. MCG

B. Vertebral Nerve accompanying Vertebral Artery

C. ICG

D. Subclavian Artery

E. Ansa Subclavia

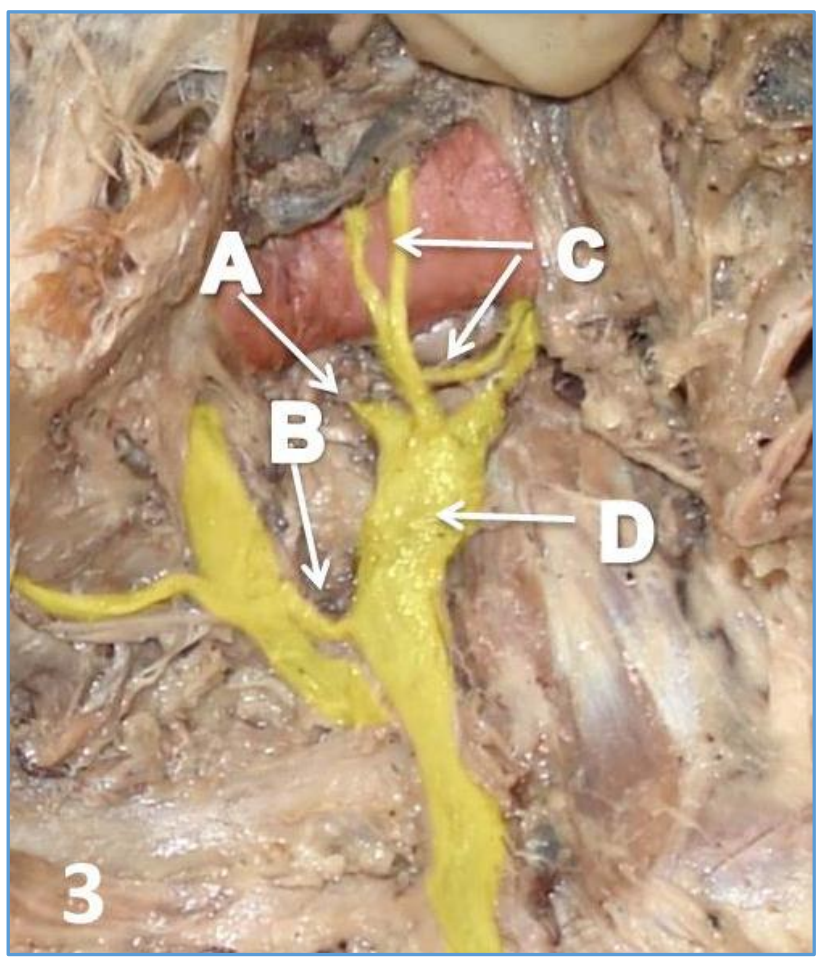

Figure 3. Right Cervical Sympathetic Trunk with Stellate Ganglion lying over the Neck of First Rib
A. GRC to $\mathrm{CB}$
B. GRC to T1
C. Ansa Subclavia
D. Stellate Ganglion

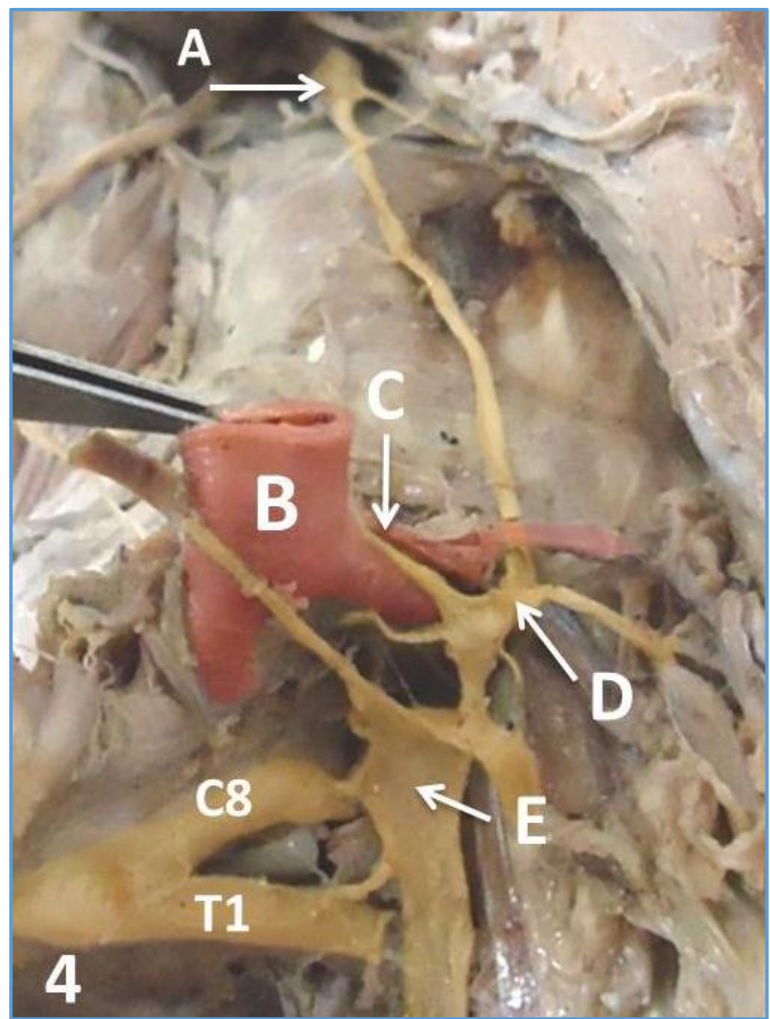

Figure 4. Right Cervical Sympathetic Trunk with Stellate Ganglion lying over the Neck of First Rib. C8 and T1 forming Lower Trunk of Brachial Plexus is also Seen
A. SCG
B. Subclavian Artery (Cut and Retracted Upwards)
C. Ansa Subclavia from VG to SG
D. Vertebral Ganglion
E. Stellate Ganglion giving GRC to C8 and T1

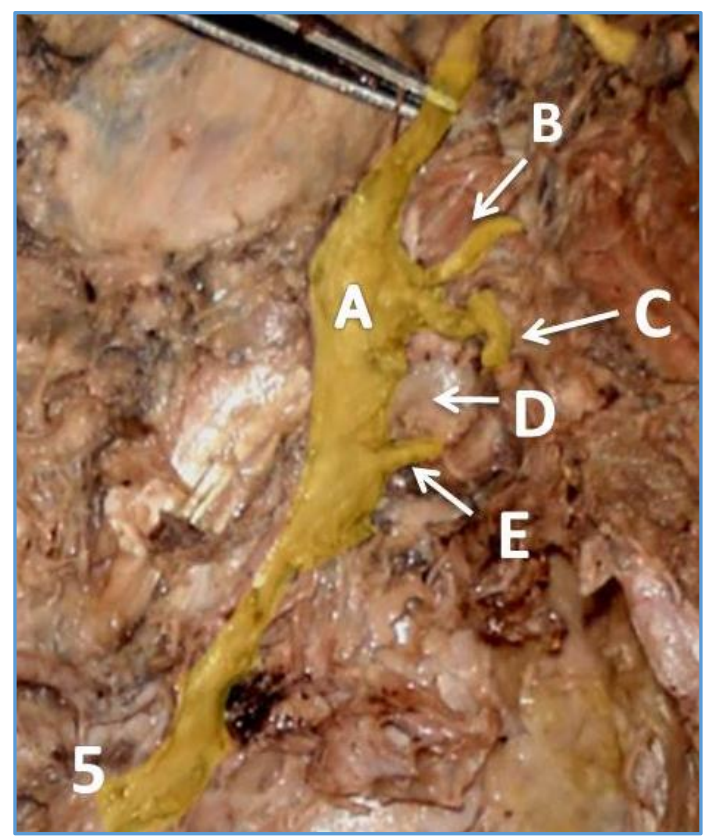

Figure 5. Left Cervical Sympathetic Trunk with Stellate Ganglion
A. Stellate Ganglion
B. GRC to $\mathrm{CB}$
C. GRC to T1
D. Second Rib
E. GRC to T2 


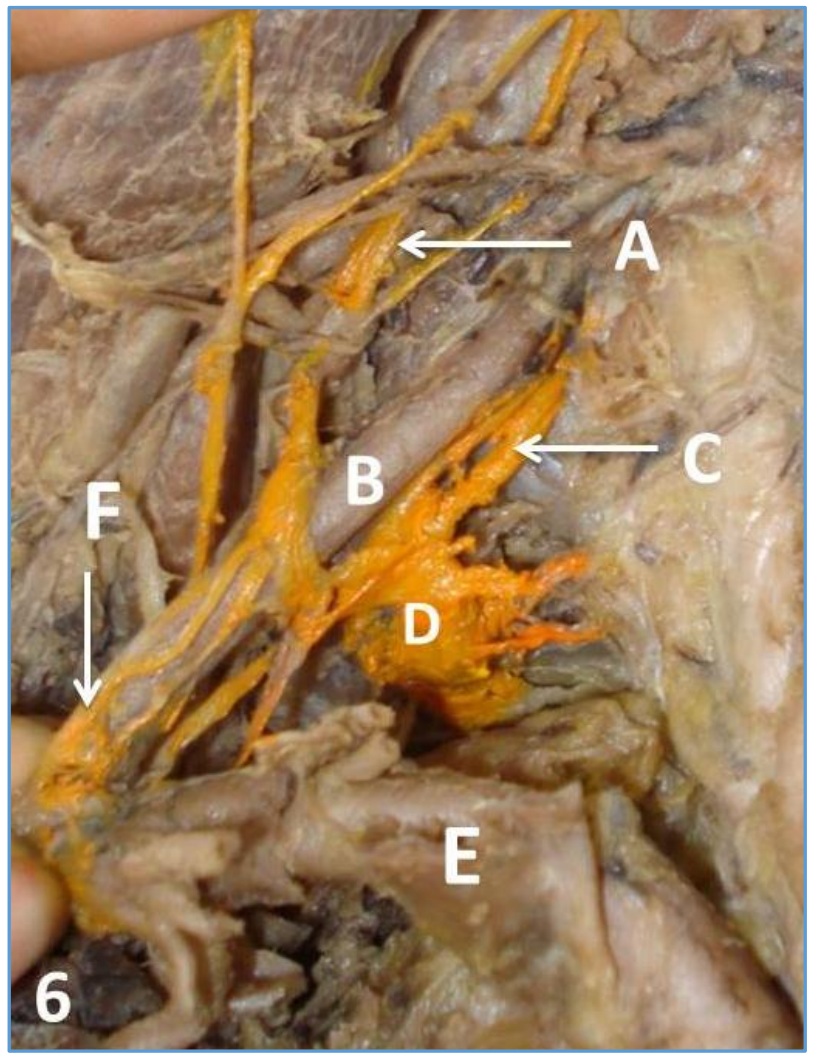

Figure 6. Left Cervical Sympathetic Chain with Stellate Ganglion

A. Sympathetic Chain

B. Vertebral Artery

C. Vertebral Nerve

D. Stellate Ganglion

E. Subclavian Artery

F. Ansa Subclavia

\section{DISCUSSION}

The autonomic ganglia and nerves are related developmentally to central nervous system. Aggregates of cells along the dorsolateral aspect of the primitive dorsal aorta from the caudal cervical to the sacral region were observed in human embryos of $6 \mathrm{~mm}$ in length. 10 Wrete noted homogeneous ganglionated cords in $10 \mathrm{~mm}$ long human embryos. The segmental character of the sympathetic trunk is well marked in the cervical region in embryos of $20-22 \mathrm{~mm}$ length. The development of the cervical sympathetic ganglia may get arrested at some stage and this leads to marked individual variations of the ganglia and its gray rami communicantes.

The sympathetic trunk extends from the base of skull to the coccyx along the anterolateral aspect of the vertebral column. The cervical portion of the sympathetic trunk lies on the prevertebral fascia ventral to the transverse process of the cervical vertebrae and dorsal to the carotid sheath Sheehan (1933) mentioned the downward direction of the cord with a slight inclination. The cervical sympathetic trunk extends upto the level of the first rib. The sympathetic trunk turns posteriorly at this level and so the long axis of the cervicothoracic ganglion becomes anteroposterior. Here, the trunk is separated from the posterior aspect of the cervical pleura by the suprapleural membrane.

SCG is considered to be formed by the fusion of first four cervical ganglia and MCG is by $5^{\text {th }}$ and $6^{\text {th }}$ cervical ganglia. The ganglion which is situated dorsal to the subclavian artery at the point of origin of vertebral artery and giving communicating rami to the seventh and eighth cervical nerves is termed "inferior cervical ganglion." 10 It is termed as "stellate ganglion" or cervicothoracic ganglion when fused with the first thoracic ganglion and is located ventral to the head of first rib, covered by pleura. The ganglia send gray rami to the corresponding spinal nerve. The term "ganglion stellatum" was extended by Woollard and Norrish (1933) to cover all the large and small ganglionated masses opposite the neck of first rib and extending upwards into the angle formed by the origin of vertebral artery from subclavian artery. ${ }^{11}$

ICG was present in $72 \%$ cases in this study. It was a small irregular ganglion having an average length of $0.82 \mathrm{~cm}$, breadth of $0.5 \mathrm{~cm}$ and thickness of $0.25 \mathrm{~cm}$. Kalsey G et al noted the length of ICG to be less than $1.5 \mathrm{~cm}$ in his works. 12 The most frequent location of ICG as observed by Becker and Grunt (1957) was over the transverse process of the seventh cervical vertebra. In the present study also in $55.6 \%$ cases, ICG was seen in the same locus. In all the cases it was present dorsal to the subclavian artery, at the point of origin of vertebral artery, in confirmation with the findings of Kuntz. ${ }^{10,13,5}$

\section{Branches: Lateral Branches}

Kuntz (1927) mentioned the formation of ICG by the fusion of the $7^{\text {th }}$ and $8^{\text {th }}$ cervical sympathetic ganglia and origin of GRC as lateral branches to $7^{\text {th }}$ and $8^{\text {th }}$ cervical spinal nerves. In the present study, GRC to C7 and C8 was seen in $47.2 \%$ cases and to C8 alone in $52.8 \%$ cases. Vertebral nerve was seen arising from the ICG in 2 cases. Lazorthes and Casson (1937) and Laux and Guerrier (1939) noted this earlier in their works.

\section{Medial Branches}

Nicholas James Mizeres (1933) and Ellison and Williams (1969) described the cardiac branches from the ICG and called it as inferior cardiac nerve. ${ }^{14}$ In this study, cardiac branches were seen in 33 cases. Fine tracheo-oesophageal branches were found in 16 cases.

\section{Vascular Branches}

Over vertebral artery and subclavian artery were present in all the cases in confirmation with the works by Kalsey G et al.

"The cervical and first thoracic ganglia are usually fused into a single structure known as cervicothoracic or stellate ganglion. These paired ganglia may be completely fused or may appear as two quite separate structures. Usually, there is a distinct isthmus between the two lobes" - White et al. In this study, the ganglionated mass, stellate ganglion was seen lying ventral to the neck of $1^{\text {st }}$ rib as an irregular mass with constrictions. A tendency to segmentation was present in the form of one constriction waist or two constriction waists. This was contrary to Oliver G and Tarnus (1958) statement, "Stellate ganglion gets its original form from embryonic sympathetic trunk without any coalescence or fusion of many ganglia." The ganglionated mass extended down upto the neck of $2^{\text {nd }}$ rib in $2(14.3 \%)$ cases. Of these, in one case $(7.1 \%)$ the $2^{\text {nd }}$ thoracic ganglion was also fused to this. Woollard and Norrish, Perlow and Vehe and Kalsey G et al had observed such findings in their study. Average length of the stellate 
ganglia was $1.67 \mathrm{~cm}$ and this measurement was $2.5 \mathrm{~cm}$ for Kalsey G et al.

\section{Branches: Lateral Branches}

Kuntz (1927) observed the formation of stellate ganglion by the fusion of the $7^{\text {th }}$ and $8^{\text {th }}$ cervical and $1^{\text {st }}$ thoracic sympathetic ganglion and the origin of GRC to C7, C8 and T1 spinal nerves. In the present study also $64.3 \%$ cases showed GRC to C7, C8 and T1, suggestive of the fusion of cervical and thoracic ganglia. Contribution from $\mathrm{T} 2$ was seen in $7.1 \%$ cases and was reported earlier in many works. Vertebral nerve was seen arising from the upper pole of the stellate ganglion in one case. Sheehan (1933) and Hoffman (1957) described about the origin of vertebral nerve from stellate ganglion in their works. ${ }^{4,15}$

\section{Medial Branches}

Nicholas James Mizeres mentioned the Cardiac branches from stellate ganglion as cervicothoracic cardiac branches. In the present study, such branches were seen in 3 cases. They formed plexus with similar branches from SCG, MCG and VG in the root of neck. Such plexuses were noted earlier by Kalsey G et al. ${ }^{12}$ Small ganglia of average length $=0.8 \mathrm{~cm}$, breadth $=0.4 \mathrm{~cm}$ and thickness $=0.2 \mathrm{~cm}$ were observed in the root of the neck, medial to the CST in the plexus formed by the cardiac nerves from the SCG, cord, MCG/ VG and ICG/stellate ganglion. Their presence in the middle and inferior cervical cardiac nerves were noted earlier by Ellison and Williams (1969). ${ }^{9}$

\section{Vascular Branches}

1 to 2 fine vascular branches over subclavian artery were present in all the cases in confirmation with the previous studies of Sheehan and Kalsey G et al (Table 1).

\section{Vertebral Nerve}

Was mentioned as an additional GRC to the $6^{\text {th }}$ or $7^{\text {th }}$ spinal nerve from the MCG or VG or ICG or from the cord, but entering the foramen transversarium accompanying the vertebral artery. In the present study it was seen arising from the upper pole of the VG in 2 cases, from the upper pole of ICG in 2 cases and from SG in 1 case. Well-defined vertebral nerves were being described by many authors. $16,17,18$

\section{Ansa Subclavia}

Two or more cords are seen connecting MCG/ VG to ICG. The anterior cord, ansa subclavia descends down looping the first part of the subclavian artery in close contact with the cervical pleura. Vieussens (1684) described ansa subclavia (ansa Vieussens) as a communicating branch uniting the inferior cervical and the first thoracic ganglia in front of the subclavian artery (Hovelacque 1927). In this study, the course of ansa subclavia from ICG or stellate ganglion to the parent ganglion was seen in $4 \%$ and $8 \%$ cases respectively. Such variations were noted by Becker and Grunt in their works. ${ }^{8}$ Subclavian plexus from ansa subclavia was described earlier by Kuntz. But no such branches were found in this study. The posterior cord was seen extending below the MCG/ VG, posterior to the subclavian artery.
The observations of the present study with respect to the ICG (72\%) and stellate ganglia (28\%) differed markedly from the usual $80 \%$ estimate of stellate ganglia for men. Only Siwe, Sheehan, Becker and Grunt indicated that the ICG was not so constantly fused with T1 in men (Table 2).

\section{CONCLUSION}

Sympathetic trunks should be identified and protected, when dissection of prevertebral fascia is performed during anterior cervical surgeries. ${ }^{19}$ Four distinct ganglia were found along the cervical sympathetic chain, of which a true stellate ganglion was found far less frequently $(28 \%)$ than the previous reports as indicated in literature. GRC, visceral and vascular branches were given by almost all ganglia studied. If no gray ramus arises from ganglion, it was seen from the cord in $86 \%$ cases. The vascular relations of the ganglia were defined. ICG was presenting posteromedial to the root of the vertebral artery and stellate ganglion behind the subclavian artery. Vertebral nerve was seen in $10 \%$ cases arising from VG, ICG or Stellate ganglion. Neurosurgeons and Anaesthetists must be aware of the less constant presence of stellate ganglion over vertebral artery. The terminology "stellate ganglion block" is also to be challenged, since stellate ganglion is not a constant one.

\section{REFERENCES}

[1] Song ZF, Sun MM, Wu ZY, et al. Anatomical study and clinical significance of the rami communicates between cervicothoracic ganglion and brachial plexus. Clinical Anatomy 2010;23(7):811-4.

[2] Wrete M. The anatomy of the sympathetic trunks in man. Journal of Anatomy 1959;93:448-59.

[3] Ghai A, Kaushik T, Wadhera R, et al. Stellate ganglion blockade-techniques and modalities. Acta Anaesthesiologica Belgica 2016;67(1):1-5.

[4] Sheehan D. On the innervations of the blood vessels of the upper extremity: some anatomical considerations. British Journal of Surgery 1933;20(79):412-24.

[5] Perlow S, Vehe KL. Variations in the gross anatomy of the stellate and lumbar sympathetic ganglia. American Journal of Surgery 1935;30(3):454-8.

[6] Pick J, Sheehan D. Sympathetic rami in man. Journal of Anatomy 1946;80:12-20.

[7] Jamieson DW, Smith DB, Anson JB. The Cervical sympathetic ganglia: an anatomical study of 100 cervicothoracic dissections. Q Bull N W Univ Med Sch 1952;26(3):219-27.

[8] Becker FR, Grunt JA. The cervical sympathetic ganglia. The Anatomical Record 1957;127(1):1-14.

[9] Ellison JP, Williams TH. Sympathetic nerve pathways to the human heart and their variations. American Journal of Anatomy 1969;124(2):149-62.

[10] Kuntz A. Development. Chap - 6. The autonomic nervous system. $4^{\text {th }}$ edn. Philadelphia: Lea and Febiger 1953: p. 117-19.

[11] Woollard HH, Norrish RE. The anatomy of the peripheral sympathetic nervous system. The British Journal of Surgery 1933;21(81):83-103. 
[12] Kalsey G, Mukherjee RN, Patnaik VVG. A comparative study of cervical sympathetic chain. Journal of Anatomical Society of India 2000;49(1):26-30.

[13] Kuntz A. Distribution of the sympathetic rami to the brachial plexus, its relation to sympathectomy affecting the upper extremity. Arch of Surgery 1927;15(6):871-7.

[14] Mizeres NJ. The cardiac plexus in man. The American Journal of Anatomy 1963;112(2):141-51.

[15] Hoffman HH. An analysis of the sympathetic trunk and rami in the cervical and upper thoracic regions in man. Ann Surg 1957;145(1):94-103.
[16] Johal J, Sharath SB, Elizabeth AL, et al. The vertebral nerve: a comprehensive review of its form and function. Journal of Clinical Neuroscience 2017;41:15.

[17] Tubbs RS, Loukas M, Remy AC, et al. The vertebral nerve revisited. Clinical Anatomy 2007;20(6):644-7.

[18] Kimmel DL. The cervical sympathetic rami and the vertebral plexus in the human fetus. Journal of Comparative Neurology 1959;112(1):141-61.

[19] Traynelis VC, Malone HR, Smith ZA, et al. Rare complications of cervical spine surgery: Horner's syndrome. Global Spine Journal 2017;7(Suppl 1):S103-S8. 